\title{
The Impacts of Different Air Pollutants on Domestic and Inbound Tourism in China
}

\author{
Xiaowei Xu, Daxin Dong*(D), Yilun Wang and Shiying Wang
}

School of Business Administration, Southwestern University of Finance and Economics, Chengdu 611130, China; xiaoweix@swufe.edu.cn (X.X.); wangyilun@smail.swufe.edu.cn (Y.W.); sherringw@smail.swufe.edu.cn (S.W.)

* Correspondence: dongdaxin@swufe.edu.cn

Received: 28 October 2019; Accepted: 6 December 2019; Published: 15 December 2019

\begin{abstract}
Previous studies have reported that air pollution negatively affects the tourism industry. This paper attempted to answer the following question: among different air pollutants, which one acts as the most adverse factor? The study was based on a sample of panel data covering 337 Chinese cities for the period between 2007 and 2016. Four pollutant indicators were inspected: $\mathrm{PM}_{2.5}$ (particulate matter 2.5 micrometers or less in size), $\mathrm{PM}_{10}$ (particulate matter 10 micrometers or less in size), $\mathrm{SO}_{2}$ (sulfur dioxide), and $\mathrm{NO}_{2}$ (nitrogen dioxide). It was found that $\mathrm{PM}_{2.5}$ had a significantly negative impact on both domestic and inbound tourist arrivals. Regarding the other three pollutant indicators, except for the negative influence of $\mathrm{NO}_{2}$ on inbound tourist arrivals, no statistically significant impact was found. This study suggests that tourism policy makers should primarily focus on $\mathrm{PM}_{2.5}$, when considering the nexus between air quality and tourism development. According to our estimates, the negative impact of $\mathrm{PM}_{2.5}$ on tourism is substantial. If the $\mathrm{PM}_{2.5}$ concentration in the ambient air increases by $1 \mu \mathrm{g} / \mathrm{m}^{3}\left(=0.001 \mathrm{mg} / \mathrm{m}^{3}\right)$, domestic and inbound tourist arrivals will decline by $0.482 \%$ and $1.227 \%$, respectively. These numbers imply an average reduction of 81,855 person-times in annual domestic tourist arrivals and 12,269 in inbound tourist arrivals in each city.
\end{abstract}

Keywords: air pollution; $\mathrm{PM}_{2.5} ; \mathrm{PM}_{10} ; \mathrm{SO}_{2} ; \mathrm{NO}_{2}$; tourist arrivals

\section{Introduction}

In recent years, the tremendous industrial growth of the Chinese economy has caused high levels of air pollution in some regions. Air pollution heavily affects public health. For instance, it was reported that air pollution has caused an average of 1.1 million premature deaths in China annually [1]. Moreover, air pollution also inhibits many economic and social activities. In particular, the adverse effect of air pollution on tourism has received increasing attention. Pollution damages tourism's development by evoking negative psychological states in tourists, reducing the aesthetics of scenic spots, harming the tourist experience, and decreasing tourism's demand (e.g., [2-4]).

Prior studies have found that air pollution negatively influences tourism's development and activities. The air pollutants examined included $\mathrm{PM}$ (particulate matter), $\mathrm{SO}_{2}$ (sulfur dioxide), $\mathrm{NO}_{2}$ (nitrogen dioxide), and so on. Among them, PM is one of the most well-known types of air pollutants. $\mathrm{PM}$ with a diameter of 2.5 micrometers or less is known as $\mathrm{PM}_{2.5}$, while that with a diameter of 10 micrometers or less is known as $\mathrm{PM}_{10}$. At present, given that social media and news agencies frequently associate $\mathrm{PM}_{2.5}$ with haze pollution, many people perceive $\mathrm{PM}_{2.5}$ and haze weather to be interchangeable concepts [5]. Additionally, some people regard $\mathrm{PM}_{2.5}$ as the only pollutant necessary for measuring the air quality index (AQI). Although $\mathrm{PM}_{2.5}$ is a dominant pollutant in haze pollution, it should be noted that, according to the World Health Organization (WHO) Air Quality Guidelines, relevant pollutants also include $\mathrm{PM}_{10}, \mathrm{NO}_{2}, \mathrm{SO}_{2}$, and ozone $\left(\mathrm{O}_{3}\right)$. Different air pollutants have been used together to calculate AQI scores and have also been found to be associated with negative health 
outcomes, such as hospital admissions, respiratory diseases, incidence of asthma symptoms, and cardiovascular disease (e.g., [6,7]). When $\mathrm{SO}_{2}$ and $\mathrm{NO}_{2}$ combine with water and sunlight, the main component of acid rain results, which can cause deforestation and destroy cultural heritage, such as ancient historical buildings and monuments.

Yan et al. [8] empirically examined the effects of different air pollutants on urban activities in China using geotagged check-in records on a Chinese social media platform, indicating that $\mathrm{SO}_{2}$ had the largest impact, followed by $\mathrm{PM}_{2.5}, \mathrm{NO}_{2}$, and $\mathrm{PM}_{10}$. They further discovered that leisure-related activities were much more sensitive to air pollution than work-related activities. To examine the impact of air pollution on the tourism industry, a number of studies have used $\mathrm{PM}_{2.5}, \mathrm{PM}_{10}$, or AQI as indicative measures of air quality (e.g., [9-12]). However, how other major air pollutants (e.g., $\mathrm{NO}_{2}$, $\mathrm{SO}_{2}$ ) influence the tourism industry in China has seldom been explored. Given that these air pollutants could all pose health threats to travelers [13] and destroy the attractiveness of destination cities to potential tourists, knowledge about how and to what extent major air pollutants exert impacts on tourism industry is required.

To address the above literature gap, this study aimed to examine the impact of air pollution on the tourism industry by taking into account four major air pollutants: $\mathrm{PM}_{2.5}, \mathrm{PM}_{10}, \mathrm{NO}_{2}$, and $\mathrm{SO}_{2}$. More specifically, this study examined whether and to what extent the different air pollutants respectively impact domestic and inbound tourism. The study's results are expected to help the Chinese government formulate better air quality control strategies, in order to maintain a sustainable tourism industry. Additionally, the results of this study could help the public health sector better understand how to issue travel advice on air pollution.

The rest of this paper proceeds as follows. Section 2 presents a literature review. Section 3 discusses the empirical model and the data used in the analyses. The estimated results of the empirical model are reported in Section 4 . Section 5 discusses the implications of the results. Section 6 concludes and talks about the directions for future research.

\section{Literature Review}

\subsection{Air Pollutants: Sources and Impacts}

$\mathrm{SO}_{2}$ and $\mathrm{NO}_{2}$ are among the major causes of smog and acid rain. $\mathrm{SO}_{2}$ arises from industrial activities that burn fossil fuels (e.g., coal, oil, and diesel) containing sulfur. Sources include but are not limited to power plants, metal processing and smelting facilities, and diesel vehicles and equipment [14,15]. Common effects of $\mathrm{SO}_{2}$ are respiratory problems and increased hospital admissions for cardiac disease [16]. $\mathrm{NO}_{2}$ is typically produced from combustion processes (e.g., heating, power generation, and engines in vehicles and ships). $\mathrm{NO}_{2}$ emissions are more likely to be clustered in densely populated urban areas and suburban industrial areas [17]. High levels of $\mathrm{NO}_{2}$ exposure could cause respiratory infections and the prevalence of bronchitic symptoms in asthmatic children aged between 5 and 14 years old [6]. $\mathrm{NO}_{2}$ exposure has also been found to be associated with lung cancer [18], mortality, hospital admissions, and respiratory diseases across all ages [6]. In addition to the health effects of $\mathrm{SO}_{2}$ and $\mathrm{NO}_{2}$, their environmental effects are largely due to the acid rain that forms from $\mathrm{SO}_{2}$ and $\mathrm{NO}_{2}$. It is well known that acid rain not only damages natural ecosystems, but also man-made materials, such as limestone, marble, and sandstone [19]. For example, the Giant Buddha at Leshan in Sichuan Province, the Longmen Grottoes in Henan Province, and the Dazu rock carvings in Chongqing, which are famous tourist attractions in China, have been reported to be at a high risk of rapid deterioration from acid rain [20]. 
Compared to $\mathrm{SO}_{2}$ and $\mathrm{NO}_{2}, \mathrm{PM}$ is more tangible and visible. Wang et al. [21] identified soil dust, vehicular emission, coal combustion, secondary aerosol, industrial emission, and biomass burning as six common sources of $\mathrm{PM}_{2.5}$ and $\mathrm{PM}_{10}$ in Beijing, China. A high concentration of PM directly reduces the visibility of air. It is also well known that PM severely damages public health [22-24]. For the Chinese population, Lu et al. [25] found that short exposures to $\mathrm{PM}_{2.5}$ and $\mathrm{PM}_{10}$ were positively associated with increases in mortality due to cardiovascular and respiratory disease. Feng et al. [26] further suggested a strong association between $\mathrm{PM}_{2.5}$ and influenza-like illness counts in the flu season.

Among the above four air pollutants, $\mathrm{PM}_{2.5}$ has received the most widespread attention in recent years. This may be due to the fact that $\mathrm{PM}_{2.5}$ is small enough to penetrate deep into the lungs, travels long distances and transcends boundaries or regions, and largely contributes to the impairment of visibility [27]. However, ignoring the impacts of other pollutants could lead to increasing health risks and detrimental climate changes in the long run. From the perspective of the tourism industry, overlooking the impact of other pollutants could lower travelers' satisfaction with respect to tourist destinations and expose travelers to more serious health threats.

\subsection{The Impact of Air Pollution on Tourism}

Two major streams of studies have examined the impacts of air pollution on tourism. One stream of literature relied on questionnaire survey tools to measure travelers' subjectively perceived level of air pollution, which is actually a psychological response to the actual air quality (e.g., [2,5,28,29]). Another stream of literature examined the impacts of actual air pollution on the tourism industry by applying different scientifically measured indices of air pollution (e.g., [9-11,30]). Table 1 presents a non-exhaustive summary of previous studies. The table reports the area studied, the period covered, and the type of pollutants studied by each research. As shown in the table, the air pollution indicators that were utilized to measure air quality varied across the different studies. It was found that $\mathrm{PM}_{2.5}$ and $\mathrm{PM}_{10}$ were two of the most frequently used air pollution indicators, followed by the comprehensive index of AQI, or the air pollution index (API). It was noticed that other air pollutants, such as $\mathrm{SO}_{2}$ and $\mathrm{NO}_{2}$, have been less focused on. Some studies also relied on the number of good or bad air-quality days within one year or the subjectively perceived level of air pollution reported in questionnaire surveys to measure air quality. 
Table 1. A non-exhaustive summary of previous studies about the impact of air pollution on tourism.

\begin{tabular}{|c|c|c|c|c|c|c|c|c|c|}
\hline \multirow[b]{2}{*}{ Literature } & \multirow[b]{2}{*}{ Area Studied } & \multirow[b]{2}{*}{ Period Covered } & \multicolumn{7}{|c|}{ Type of Pollutants Studied } \\
\hline & & & $\mathbf{P M}_{2.5}$ & $\mathbf{P M}_{10}$ & $\mathrm{SO}_{2}$ & $\mathrm{NO}_{2}$ & $\begin{array}{c}\mathrm{AQI} \\
\text { (or API) }\end{array}$ & Other Objective Indicators & $\begin{array}{l}\text { Perceived } \\
\text { Pollution }\end{array}$ \\
\hline Anaman and Looi [31] & Brunei Darussalam & 1995M1-1999M9 & & & & & & $\begin{array}{l}\text { dummy variable for } \\
\text { haze-related pollution }\end{array}$ & \\
\hline Becken et al. [2] & China & 2014 & & & & & & & $\sqrt{ }$ \\
\hline Chen et al. [32] & Sun Moon Lake Scenic Area, Taiwan, China & 2004M1-2011M12 & & & & & & days of bad air quality & \\
\hline Deng et al. [30] & 31 provinces in China & $2001-2013$ & & & & & & industrial waste gas emission & \\
\hline Dong et al. [9] & 274 cities in China & $2009-2012$ & & $\sqrt{ }$ & & & & & \\
\hline Dong et al. [10] & 337 cities in China & $2004-2013$ & $\sqrt{ }$ & & & & & & \\
\hline Law and Cheung [33] & Hong Kong, China & 2003 & & & & & & & $\sqrt{ }$ \\
\hline Li et al. [34] & Beijing, China & 2014 & & & & & & & $\sqrt{ }$ \\
\hline Liu et al. [11] & 17 provinces in China & 2005-2015 & $\sqrt{ }$ & & & & & & \\
\hline Peng and Xiao [35] & Beijing, China & 2016 & & & & & & & $\sqrt{ }$ \\
\hline Poudyal et al. [3] & Great Smoky Mountain National Park, USA & 1988M3-2009M12 & & & & & & visibility of air & \\
\hline Qiao et al. [36] & China & 2015 & & & & & & & $\sqrt{ }$ \\
\hline Sun et al. [12] & 28 cities in China & 1999-2015 & $\sqrt{ }$ & & & & & & \\
\hline Tang et al. [37] & Beijing, China & 2004M1-2015M12 & & & & & $\sqrt{ }$ & & \\
\hline Wang and Wang [38] & 35 OECD countries & 1995-2014 & & & & & & $\mathrm{CO}_{2}$ emission & \\
\hline Wang et al. [39] & 11 cities in China & 2016M1D1-2016M12D31 & & & & & $\sqrt{ }$ & & \\
\hline Xu and Reed [28] & China & 2006-2014 & & & & & & & $\sqrt{ }$ \\
\hline $\mathrm{Xu}$ and Reed [29] & Shanghai, China & 2011M12-2016M10 & $\sqrt{ }$ & & & & & & $\sqrt{ }$ \\
\hline Xu et al. [40] & 174 cities in China & 1998-2016 & $\sqrt{ }$ & & & & & & \\
\hline Yan et al. [8] & 251 cities in China & 2015M1D1-2016M10D30 & $\sqrt{ }$ & $\sqrt{ }$ & $\sqrt{ }$ & $\sqrt{ }$ & $\sqrt{ }$ & $\mathrm{CO}$ & \\
\hline Yoon [41] & Seoul, South Korea & 2015M4-2017M2 & & $\sqrt{ }$ & & & & & \\
\hline Zhang et al. [5] & Beijing, China & 2014 & & & & & & & $\sqrt{ }$ \\
\hline Zhang et al. [4] & Thailand & 2001-2017 & & & & & & $\mathrm{CO}_{2}$ emission & \\
\hline Zhou et al. [42] & 24 cities in China & 2007M1-2012M12 & & & & & $\sqrt{ }$ & & \\
\hline Zhou et al. [43] & Beijing, China & 2005-2016 & $O$ & $\sqrt{ }$ & $O$ & $O$ & & days of good air quality & \\
\hline
\end{tabular}

Note: (1) The symbol " $\sqrt{ }$ " indicates that the corresponding air pollutant indicator was used in the study and demonstrated a statistically significant impact on tourism. The symbol

" $O$ " indicates that the corresponding air pollutant indicator was used in the study but did not demonstrate statistical significance. (2) The sample period covered in each study is described in the column "Period Covered". For the study based on the questionnaire survey to measure the perceived degree of air pollution, rather than the objectively measured level of air pollution, the "Period Covered" refers to the time of conducting questionnaire survey. 
Overall, there was no consensus on the selection of air pollution indicators in the literature. The choice of air pollution indicator largely depended on the degree of convenience in data collection. Although different pollutants all reduce the quality of air, their respective impacts on tourist activities may be different. Interestingly, Yan et al. [8] reported that $\mathrm{PM}_{2.5}, \mathrm{PM}_{10}, \mathrm{SO}_{2}$, and $\mathrm{NO}_{2}$ all depressed humans' leisure-relevant behaviors, while Zhou et al. [43] reported that only $\mathrm{PM}_{10}$ had a statistically significant impact. As an extension of these two studies, our study also examined and compared the regression results for different pollutants. However, differently from Yan et al. [8] who used geotagged social media check-in data of "Weibo" covering 2015 and 2016, and Zhou et al. [43], who solely concentrated on one city in China (the city of Beijing), this study used a city-level sample, including 337 Chinese cities and covering the period between 2007 and 2016. Based on a wider sample, this study was able to examine the impact of air pollution on both inbound and domestic tourism more precisely from an aggregate perspective.

\section{Empirical Model and Data}

\subsection{Model}

The study was based on a city-level sample with panel data structure, consisting of both temporal and spatial dimensions. Following the previous studies investigating the pollution-tourism nexus (e.g., $[12,31,32,39])$, it was assumed that the impacts of air pollution and other explanatory variables on tourism could be captured by a linear econometric regression model. To be precise, in this study the following panel data econometric model was used:

$$
y_{i t}=x_{i t} \beta+s_{i}+u_{t}+\varepsilon_{i t}
$$

where $y_{i t}$ is the dependent variable in city $i$ during period $t . x_{i t}$ refers to a vector of explanatory variables. $s_{i}$ is the section-fixed effect, and $u_{t}$ is the time-fixed effect. $\varepsilon_{i t}$ is the error term. $\beta$ is a vector of parameters to be estimated.

In this study, we investigated the impacts of air pollution on both domestic tourism and inbound tourism. Thus, we separately considered two dependent variables: Arrivalsomestic, the domestic tourist arrivals (in 10,000 person-times), and Arrivals ${ }^{\text {inbound }}$, the inbound tourist arrivals (in 10,000 person-times). As usual, in the econometric regressions, we used the logarithmic values of these two variables to deal with the scaling problem. Accordingly, the variations of dependent variables are expressed as percentage changes.

Among the explanatory variables, the core variable of interest was the air pollutant indicator. In this study, we inspected four important air pollution indicators: $\mathrm{PM}_{2.5}, \mathrm{PM}_{10}, \mathrm{SO}_{2}$, and $\mathrm{NO}_{2}$. These variables of air pollutants are expressed by their degrees of concentration density $\left(\mathrm{mg} / \mathrm{m}^{3}\right)$ in ambient air.

A set of control variables was contained in the regressions: Scenic, Hotel, Road, GovSize, Population, and GDPpc. (i) The first control variable, Scenic, measures the abundance of local tourism endowment. It was calculated by the logarithmic value of the number of $4 \mathrm{~A}-$ and $5 \mathrm{~A}-$-rated scenic spots within each city. Since a $5 \mathrm{~A}$-rated scenic spot is typically considered as much more attractive than a $4 \mathrm{~A}$ spot $[9,30]$, we assumed that one $5 \mathrm{~A}$ spot equalled three $4 \mathrm{~A}$ spots. To avoid the problem of logarithmic computation when a city has zero $4 \mathrm{~A}$ and $5 \mathrm{~A}$ spots, we assigned a value of 0.01 to the number of scenic spots when it was actually zero. (ii) The second control variable, Hotel, measured the availability of tourism-specific infrastructure. We used the star-rated hotels to proxy this, since hotels are one of the most crucial tourism infrastructures. This variable was calculated by the ratio of the number of hotels divided by local population (in ten thousand). (iii) The third variable was Road, the length of road $(\mathrm{km})$ per area $\left(\mathrm{km}^{2}\right)$. This was an indicator of the transportation infrastructure. (iv) GovSize was the government size, measured by the ratio of local government expenditure to GDP. This variable was used to capture the impact of the government on local tourism's development. (v) Population was the logarithmic value of the local population (in ten thousand), as a control variable 
for the potential economies of scale in tourism development. (vi) The last control variable was GDP $p c$, the logarithmic value of real GDP per capita (RMB). The nominal GDP was deflated, taking 2000 as the base year. Since previous studies have found that tourism might have impacts on economic and social development, which are directly linked to the values of the control variables in the current period, we lagged these control variables for three periods to mitigate the potential endogeneity problem. The idea is that the three-period-lagged values of the control variables probably affect the current value of the dependent variable (through their impacts on the current values of the control variables), but the current dependent variable has no effect on the past value of the control variables. That way, the potential endogeneity caused by reverse causality from the dependent variable to explanatory variables was mitigated. Definitely, one limitation of using the lagged values of control variables is that the estimated coefficients of them may not accurately reflect the impacts of the variables in the current period. However, given the large benefit of using this approach to mitigate the endogeneity issue, its limitation was deemed acceptable, and hence, it has been widely used in applied economics research (e.g., [44,45]).

\subsection{Data}

The data of $\mathrm{PM}_{2.5}$ were collected from NASA's Global Annual $\mathrm{PM}_{2.5}$ Grids data [46,47]. The data of $\mathrm{PM}_{10}, \mathrm{SO}_{2}$, and $\mathrm{NO}_{2}$ were mainly extracted from a series of yearly published environmental quality reports-“The Report on the State of the Environment of China" [48-50]. These reports were written by China's Ministry of Environmental Protection (MEP), and later, by the Ministry of Ecology and Environment (MEE). These reports provided detailed official data of air quality in different areas of China since 2007. The reports did not offer city-level air pollution data for the years 2013 and 2015. We checked the China Statistical Yearbook on Environment and several province-level statistical yearbooks to supplement the missing data for some cities in 2013 and 2015, as well as some observations in other years. It is worth mentioning that the MEP, and later, the MEE, have also reported the $\mathrm{PM}_{2.5}$ data in recent years. However, the available sample size was much smaller compared to that based on NASA's data. That is why we relied on the latter data source for $\mathrm{PM}_{2.5}$ in our empirical analysis. In fact, an examination of the overlapping sample of these two data sources would make it clear that they are both reliable and highly correlated, though the reported values are not directly comparable, due to the technological disparity in measurement. NASA's PM $_{2.5}$ data were constructed on the basis of the information supplied by the remote sensing measurements of satellites, whereas the data offered by the MEP and MEE were from the direct measurements in local observation stations. Although there were uncertainties associated with the remote sensing measurements (for example, affected by weather and the precision of the electrical instruments), the accuracy and reliability of the $\mathrm{PM}_{2.5}$ grids data have been highly appreciated. In fact, both data sources have been widely utilized in previous research (e.g., $[8,9,11,12,42])$. The data from the two data sources were highly correlated. For example, for the sample cities in the year of 2016, the Pearson correlation coefficient between $\mathrm{PM}_{2.5}$ values from the two data sources was 0.753 , indicating a strong positive correlation.

The data of the dependent variables Arrivals domestic and Arrivals ${ }^{\text {inbound }}$, and the control variables Hotel, Road, GovSize, Population, and GDPpc during the period 2007-2013 came from the China Statistical Yearbook for Regional Economy. For the period covered, this yearbook provided city-level data for almost all Chinese cities above the prefecture-level, though with occasional missing values. The data between 2014 and 2016 were obtained from the EPS database, available at its website: http:/ / www.epschinadata.com. In addition, we checked different province-level statistical yearbooks or utilized the linear interpolation method to supplement some missing observations. The data of Scenic were collected from the public information released by the tourism-relevant local governmental sectors in different provinces.

Ultimately, our sample was comprised of unbalanced panel data covering 337 Chinese cities for the period between 2007 and 2016. This sample covered almost all regions in Mainland China, including all four province-level municipalities (Beijing, Tianjin, Shanghai, and Chongqing) and all 
prefecture-level administrative districts except Sansha City and Danzhou City of Hainan Province. Sansha and Danzhou, which were respectively established in 2012 and 2015, were excluded due to lack of statistical data. Table 2 shows the summary statistics for the variables used in empirical analyses. It is clear from the table that there were rich heterogeneities among the sample cities. The sample contained both less developed and well developed, small and large, and clean and severely polluted cities. Some cities had highly developed tourism industries, but the tourism size in some cities was quite small. Overall, our sample was highly representative and able to provide sufficient information on the general situation of China.

It is notable that the different air pollutants are probably correlated. Indeed, since human activities often emit more than one kind of pollutant, a district may be polluted by multiple pollutants simultaneously [51,52]. Moreover, since different pollutants may have complex chemical and physical interactions within the air, the degree of air pollution caused by one pollutant may be exacerbated by another one. Considering this, we had a concern that if the correlation among different pollutants was sufficiently high, there would be no way to distinguish different pollutants and use traditional econometric regressions to estimate their individual impacts on tourism. Table 3 shows the Pearson correlation coefficients among the four pollutants. From the table, we see that different pollutants are indeed positively correlated, as expected. However, the correlation coefficients are not very high and do not exceed 0.5. Thus, the indices of these four pollutants reflect different aspects of air pollution, and can be considered separately as different explanatory variables in the regression model.

Table 2. Summary statistics.

\begin{tabular}{|c|c|c|c|c|c|c|c|}
\hline \multicolumn{2}{|c|}{ Variable } & \multirow{2}{*}{$\begin{array}{l}\text { Unit } \\
10^{4} \text { person-times }\end{array}$} & \multirow{2}{*}{$\begin{array}{l}\text { Obs } \\
2892\end{array}$} & \multirow{2}{*}{$\begin{array}{l}\text { Mean } \\
6.832\end{array}$} & \multirow{2}{*}{$\begin{array}{l}\text { SD } \\
1.229\end{array}$} & \multirow{2}{*}{$\begin{array}{l}\text { Min } \\
1.033\end{array}$} & \multirow{2}{*}{$\frac{\text { Max }}{10.658}$} \\
\hline Dependent & Arrivals domestic & & & & & & \\
\hline Variable & Arrivals ${ }^{\text {inbound }}$ & $10^{4}$ person-times & 2952 & 1.447 & 2.311 & -9.210 & 7.106 \\
\hline \multirow{4}{*}{$\begin{array}{l}\text { Air } \\
\text { Pollutant }\end{array}$} & $P M_{2.5}$ & $\mathrm{mg} / \mathrm{m}^{3}$ & 3364 & 0.033 & 0.018 & 0.002 & 0.087 \\
\hline & $P M_{10}$ & $\mathrm{mg} / \mathrm{m}^{3}$ & 2376 & 0.083 & 0.033 & 0 & 0.436 \\
\hline & $\mathrm{SO}_{2}$ & $\mathrm{mg} / \mathrm{m}^{3}$ & 2379 & 0.033 & 0.018 & 0.002 & 0.148 \\
\hline & $\mathrm{NO}_{2}$ & $\mathrm{mg} / \mathrm{m}^{3}$ & 2379 & 0.030 & 0.012 & 0.002 & 0.069 \\
\hline \multirow{6}{*}{$\begin{array}{l}\text { Control } \\
\text { Variable }\end{array}$} & Scenic & - & 3367 & -0.334 & 2.640 & -4.605 & 4.331 \\
\hline & Hotel & - & 3367 & 0.143 & 0.226 & 0.003 & 4.338 \\
\hline & Road & $\mathrm{km} / \mathrm{km}^{2}$ & 3367 & 0.767 & 0.497 & 0.003 & 2.249 \\
\hline & GovSize & - & 3367 & 0.189 & 0.179 & 0.040 & 3.581 \\
\hline & Population & $10^{4}$ persons & 3367 & 5.665 & 0.877 & 2.077 & 7.996 \\
\hline & $G D P p c$ & $\mathrm{RMB}$ & 3367 & 9.720 & 0.731 & 7.613 & 11.874 \\
\hline
\end{tabular}

Note: (1) The variables Scenic, Hotel, and GovSize have no unit. Scenic is the number of scenic spots. Hotel is the ratio of the number of hotels divided by local population (in ten thousand). GovSize is the ratio of government spending to GDP. (2) The variables Arrivals domestic, Arrivals inbound, Scenic, Population, and GDPpc were log-transformed. (3) The abbreviations "Obs", "SD", "Min", and "Max" in the first row denote "Observations", "Standard Deviation", "Minimum", and "Maximum", respectively.

Table 3. Correlation coefficients among the four pollutants.

\begin{tabular}{ccccc}
\hline & $\boldsymbol{P M}_{\mathbf{2 . 5}}$ & $\boldsymbol{P M}_{\mathbf{1 0}}$ & $\mathrm{SO}_{\mathbf{2}}$ & $\mathrm{NO}_{\mathbf{2}}$ \\
\hline $\mathrm{PM}_{2.5}$ & 1 & & & \\
$\mathrm{PM}_{10}$ & 0.329 & 1 & & \\
$\mathrm{SO}_{2}$ & 0.309 & 0.403 & 1 & \\
$\mathrm{NO}_{2}$ & 0.435 & 0.492 & 0.401 & 1 \\
\hline
\end{tabular}

\section{Results}

The regression results for Equation (1) are reported in this section. Section 4.1 discusses the estimated impacts of air pollutants on domestic tourism. Section 4.2 discusses the circumstances regarding inbound tourism. 


\subsection{Impacts of Air Pollutants on Domestic Tourism}

Table 4 shows the estimated influences of different air pollutants on domestic tourism. First, we focused on $\mathrm{PM}_{2.5}$. As reported in column (1) of the table, the coefficient of $\mathrm{PM}_{2.5}$ was -4.815 , statistically significant at the $1 \%$ level. This implies that if the $\mathrm{PM}_{2.5}$ density increased by $1 \mu \mathrm{g} / \mathrm{m}^{3}$ $\left(=0.001 \mathrm{mg} / \mathrm{m}^{3}\right)$, domestic tourist arrivals would decline by $0.482 \%$. Given that the mean value of annual domestic tourist arrivals among our sample cities was around 17 million person-times, this magnitude corresponds to a decline of 81,855 person-times in tourist arrivals. This is indeed a huge loss. Regarding the control variables, we found that the coefficients of Scenic and Hotel were both significantly positive, consistent with the straightforward idea that more scenic spots and more tourism infrastructure benefit tourism. Government size, GovSize, had a significant positive coefficient, perhaps because local government plays an important role in tourism development in China. The coefficient of GDP per capita, GDP $p c$, was also positive, indicating that, on average, Chinese tourists considered more developed regions to be more attractive. The variables Road and Population did not show significant impacts on domestic tourism.

Table 4. The impacts of air pollutants on domestic tourism.

\begin{tabular}{|c|c|c|c|c|c|c|c|c|}
\hline \multirow{3}{*}{ Variable } & \multicolumn{4}{|c|}{$\mathbf{P M}_{2.5}$} & \multirow{2}{*}{$\mathbf{P M}_{10}$} & \multirow{2}{*}{$\mathrm{SO}_{2}$} & \multirow{2}{*}{$\mathrm{NO}_{2}$} & \multirow{2}{*}{$\begin{array}{l}\text { All } \\
\text { Pollutants }\end{array}$} \\
\hline & Baseline & $\begin{array}{l}\text { System } \\
\text { GMM }\end{array}$ & $\begin{array}{l}\text { Smaller } \\
\text { Sample }\end{array}$ & $\begin{array}{l}\text { Tourism } \\
\text { Receipts }\end{array}$ & & & & \\
\hline & (1) & $(2)$ & (3) & (4) & (5) & $(6)$ & $(7)$ & (8) \\
\hline$P M_{2.5}$ & $-4.815^{* * *}$ & $-2.136^{*}$ & $-5.304 * * *$ & $-4.394^{* *}$ & & & & $-5.376^{* * *}$ \\
\hline$P M_{10}$ & & & & & 0.558 & & & 0.817 \\
\hline $\mathrm{SO}_{2}$ & & & & & & -0.589 & & -0.768 \\
\hline $\mathrm{NO}_{2}$ & & & & & & & 0.001 & 0.070 \\
\hline Scenic & $0.016^{* * *}$ & $0.138^{* * *}$ & $0.011^{* *}$ & $0.024^{* * *}$ & $0.012 * *$ & $0.012^{* *}$ & $0.012 * *$ & $0.011^{* *}$ \\
\hline Hotel & $0.176^{* * *}$ & 0.068 & $0.147^{* * *}$ & 0.055 & $0.145^{* * *}$ & $0.149 * * *$ & $0.147^{* * *}$ & $0.146^{* * *}$ \\
\hline Road & -0.006 & $0.275^{* *}$ & $0.091 *$ & $-0.199 * * *$ & $0.111^{* *}$ & $0.111^{* *}$ & $0.113^{* *}$ & 0.084 \\
\hline GovSize & $0.539 * * *$ & -0.238 & $0.594^{* *}$ & 0.313 & $0.569 * *$ & $0.555^{* *}$ & $0.551 * *$ & $0.598^{* *}$ \\
\hline Population & 0.310 & $0.805^{* * *}$ & 0.238 & 0.014 & 0.267 & 0.280 & 0.282 & 0.220 \\
\hline$G D P p c$ & $0.192 * *$ & 0.048 & $0.227^{* *}$ & $0.298^{* * *}$ & $0.230 * *$ & $0.227 * *$ & $0.228^{* *}$ & $0.231 * *$ \\
\hline Observations & 2892 & 2892 & 2033 & 2783 & 2033 & 2036 & 2036 & 2033 \\
\hline Cities & 337 & 337 & 328 & 337 & 328 & 328 & 328 & 328 \\
\hline$R^{2}$ & 0.776 & - & 0.815 & 0.738 & 0.814 & 0.814 & 0.814 & 0.816 \\
\hline
\end{tabular}

To investigate the robustness of our finding on the harmful effect of $\mathrm{PM}_{2.5}$, we conducted three further robustness analyses on the result. (i) One concern is that air pollution and tourism might have complex reciprocal interactions [53], which might cause the endogeneity problem in the econometric estimation [9]. System GMM (general method of moments) estimation is a reliable approach to deal with the endogeneity problem in a "short panel" with many individuals but a small number of periods like our data structure. Column (2) of the table reports the result of System GMM estimation, which shows a significant negative coefficient of -2.136 . The magnitude was smaller than that of the coefficient in column (1), but was still quite considerable. (ii) Comparing the number of observations of $\mathrm{PM}_{2.5}$ and the other three pollutants, as previously reported in Table 2, we found that $\mathrm{PM}_{2.5}$ data had more observations than the other three pollutants. This raised the concern that the regression results regarding $\mathrm{PM}_{2.5}$ might not be fully comparative to those for the other pollutants, due to the difference in sample size. To address this concern, we deleted the sample points that had data for $\mathrm{PM}_{2.5}$ but not for the other pollutants, and repeated the regression based on the smaller sample obtained. The estimated coefficient of $\mathrm{PM}_{2.5}$ was -5.304 , as displayed in column (3). Clearly, our previous finding held. (iii) To date, we have only considered the impact of $\mathrm{PM}_{2.5}$ on tourist arrivals. In column (4), we report the estimate when the dependent variable was the logarithmic value of tourism receipts (in 100 million RMB, deflated based on the year 2000 price), instead of tourist arrivals. The estimated coefficient was 
-4.394 , very close to that in column (1). Given that the mean annual domestic tourism receipt was 12 billion RMB, the coefficient implies that, on average, a $1 \mu \mathrm{g} / \mathrm{m}^{3}$ increase in $\mathrm{PM}_{2.5}$ concentration would cause a reduction of 53 million RMB (approximately 8 million US dollars) in domestic tourism receipts at the city level. In a nutshell, combining the results in columns (1)-(4) together, we are able to claim that $\mathrm{PM}_{2.5}$ had a robust and significant negative impact on domestic tourism.

Next, we examined the effects of $\mathrm{PM}_{10}, \mathrm{SO}_{2}$, and $\mathrm{NO}_{2}$ on domestic tourism, respectively. As reported in column (5), the estimation did not detect a statistically significant impact from $\mathrm{PM}_{10}$. Column (6) reports the estimated coefficient of $\mathrm{SO}_{2}$, which was not significant either. Similarly, as can be seen from column (7), $\mathrm{NO}_{2}$ did not significantly affect domestic tourism.

Lastly, we put all four pollutants into one regression equation and reported the estimates in column (8). The result still showed a significant negative coefficient for $\mathrm{PM}_{2.5}$, but not for $\mathrm{PM}_{10}, \mathrm{SO}_{2}$, or $\mathrm{NO}_{2}$. This result supported the findings from columns (1)-(7) when we checked the impacts of the four pollutants one by one.

\subsection{Impacts of Air Pollutants on Inbound Tourism}

Table 5 demonstrates the impacts of air pollutants on inbound tourism. Column (1) reports the baseline estimates for $\mathrm{PM}_{2.5}$. The statistically significant coefficient was -12.269 , indicating that inbound tourist arrivals would decline by $1.227 \%$ in response to a $1 \mu \mathrm{g} / \mathrm{m}^{3}\left(=0.001 \mathrm{mg} / \mathrm{m}^{3}\right)$ increase in $\mathrm{PM}_{2.5}$ concentration. Given that the mean value of annual inbound tourist arrivals in our sample cities was nearly 1 million person-times, this magnitude indicates a decline of 12,269 person-times in tourist arrivals. This loss is indeed substantial. The control variables were generally not statistically significant, indicating that inbound tourists were not sensitive to the economic and social characteristics of destination cities.

Table 5. The impacts of air pollutants on inbound tourism.

\begin{tabular}{|c|c|c|c|c|c|c|c|c|}
\hline \multirow{3}{*}{ Variable } & \multicolumn{4}{|c|}{$\mathbf{P M}_{2.5}$} & \multirow{2}{*}{$\mathbf{P M}_{10}$} & \multirow{2}{*}{$\mathrm{SO}_{2}$} & \multirow{2}{*}{$\mathrm{NO}_{2}$} & \multirow{2}{*}{$\begin{array}{l}\text { All } \\
\text { Pollutants }\end{array}$} \\
\hline & Baseline & $\begin{array}{l}\text { System } \\
\text { GMM }\end{array}$ & $\begin{array}{l}\text { Smaller } \\
\text { Sample }\end{array}$ & $\begin{array}{l}\text { Tourism } \\
\text { Receipts }\end{array}$ & & & & \\
\hline & (1) & (2) & (3) & (4) & (5) & (6) & (7) & (8) \\
\hline$P M_{2.5}$ & $-12.269^{* * *}$ & $-12.517^{* *}$ & $-7.185^{*}$ & $-8.259 *$ & & & & $-7.359 *$ \\
\hline$P M_{10}$ & & & & & 0.924 & & & 1.780 \\
\hline $\mathrm{SO}_{2}$ & & & & & & -0.567 & & 0.804 \\
\hline $\mathrm{NO}_{2}$ & & & & & & & $-5.069 *$ & $-6.625 *$ \\
\hline Scenic & 0.002 & $0.455^{* * *}$ & 0.011 & $0.046^{* * *}$ & 0.012 & 0.012 & 0.010 & 0.008 \\
\hline Hotel & 0.105 & 2.034 * & 0.085 & 0.089 & 0.080 & $0.086^{*}$ & 0.094 * & $0.086^{*}$ \\
\hline Road & -0.182 & $-1.071^{* *}$ & $-0.283^{* *}$ & -0.198 & -0.262 * & -0.260 * & -0.239 * & -0.268 * \\
\hline GovSize & $-0.472^{* *}$ & $-11.859^{* * *}$ & 0.090 & $-0.656^{* *}$ & 0.064 & -0.024 & -0.021 & 0.094 \\
\hline Population & -0.246 & -0.306 & -0.667 & -1.150 & -0.623 & -0.643 & -0.684 & -0.733 \\
\hline GDPpc & 0.031 & 0.152 & -0.052 & 0.034 & -0.039 & -0.053 & -0.047 & -0.033 \\
\hline Observations & 2952 & 2952 & 2111 & 2941 & 2111 & 2114 & 2114 & 2111 \\
\hline Cities & 337 & 337 & 324 & 337 & 324 & 324 & 324 & 324 \\
\hline$R^{2}$ & 0.214 & - & 0.266 & 0.100 & 0.265 & 0.262 & 0.264 & 0.270 \\
\hline
\end{tabular}

Statistical significance: ${ }^{*} p<10 \%,{ }^{* *} p<5 \%,{ }^{* * *} p<1 \%$.

Three robustness analyses on the impact of $\mathrm{PM}_{2.5}$ are reported in columns (2)-(4). (i) In column (2), the System GMM estimates are reported. The coefficient of $\mathrm{PM}_{2.5}$ was -12.517 , very close to that reported in column (1). (ii) In column (3), we relied on a smaller sample, in which all sample points had data for all four pollutants. The estimated coefficient of $\mathrm{PM}_{2.5}$ was -7.185 . This coefficient was still significantly negative, supporting the result in column (1). (iii) In column (4), we used the logarithmic value of inbound tourism receipts (in 100 million RMB, deflated based on the year 2000 price) as the dependent variable, instead of tourist arrivals. The estimated significant negative coefficient of -8.259 supported the finding that $\mathrm{PM}_{2.5}$ harmed inbound tourism. The magnitude implies that inbound tourism receipts would decline by 7 million RMB (approximately 1 million US dollars) after $\mathrm{PM}_{2.5}$ 
concentration increased by $1 \mu \mathrm{g} / \mathrm{m}^{3}$, given that the average inbound tourism receipt of the sample cities was 893 million RMB per year.

Next, we checked the impacts of the other three air pollutant indices. The impacts of $\mathrm{PM}_{10}$ and $\mathrm{SO}_{2}$ were not significant, as reported in columns (5) and (6), respectively. From column (7), it was found that the impact of $\mathrm{NO}_{2}$ was negative and statistically significant at the $10 \%$ level. This implies that inbound tourists were responsive to the rise of $\mathrm{NO}_{2}$ pollution.

In column (8), we report the estimates after we put all four pollutants together within one regression equation. The coefficient of $\mathrm{PM}_{2.5}$ was -7.359 and maintained statistical significance. $\mathrm{PM}_{10}$ and $\mathrm{SO}_{2}$ did not have significant impacts. The coefficient of $\mathrm{NO}_{2}$ was significantly negative, analogous to that in column (7).

\section{Discussion and Implications}

\subsection{Discussion}

The analyses in this study provide three important findings. Firstly, it was found that air pollution, measured by $\mathrm{PM}_{2.5}$, shows a harmful effect on both domestic and inbound tourism. This finding is consistent with previous studies (e.g., [29-31,33]) that reported the negative impact of air pollution on tourism. As our sample covered a wide geographic area and a long time-span, this study supplements the prior literature by providing further evidence on the pollution-tourism nexus. As claimed in the previous studies, policy makers should take actions to mitigate the air pollution problem for the purpose of boosting tourism. Good air quality is a substantially attractive characteristic for tourist destination cities.

Secondly, different pollutants were found to exert different impacts on the tourism industry. According to our estimates, the most adverse pollutant indicator is $\mathrm{PM}_{2.5}$, which was compared to $\mathrm{PM}_{10}, \mathrm{SO}_{2}$, and $\mathrm{NO}_{2}$. The estimates demonstrate a robust, large, and statistically significant impact of $\mathrm{PM}_{2.5}$ on tourism. Given that $\mathrm{PM}_{2.5}$ can be especially harmful, due to its relatively small size compared to other air pollutants, it has attracted more public attention through microblogging platforms such as Weibo [54]. In addition, $\mathrm{PM}_{2.5}$ is more closely associated with the reduction of visibility than some other pollutants $[55,56]$. Travelers are highly concerned about the low visibility issue, as it can reduce the aesthetics of tourist attractions [5,57] and interrupt traffic by causing flight delays or cancellations, or highway closures [58]. Regarding the other three pollutants, $\mathrm{PM}_{10}, \mathrm{SO}_{2}$, and $\mathrm{NO}_{2}$, the estimation results show that they do not have a similar impact to that of $\mathrm{PM}_{2.5}$. No statistically significant effect of $\mathrm{PM}_{10}$ and $\mathrm{SO}_{2}$ on tourism was detected. $\mathrm{NO}_{2}$ was found to negatively influence inbound tourism, but it does not significantly affect domestic tourism. This finding is novel and not consistent with some previous studies, including Yan et al. [8], Yoon [41], and Zhou et al. [43], which reported a negative effect of $\mathrm{PM}_{10}, \mathrm{SO}_{2}$, or $\mathrm{NO}_{2}$ on tourism. The different impacts of $\mathrm{NO}_{2}$ on domestic and inbound tourism are especially interesting. There may be at least two plausible explanations. The first reason is relevant to the degree of perception and concern about air pollution in different tourist groups. The previous studies have confirmed that people's opinions about the severity of air pollution largely depend on their sociodemographic status, including education, knowledge, income, and so on $[59,60]$. For instance, tourists with higher income levels are typically more sensitive to air pollution than those with low income [39]. It is possible that, on average, the sociodemographic characteristics of inbound tourists make them more aware of the damage of $\mathrm{NO}_{2}$, compared to domestic tourists in China. The second reason is relevant to the differences in the health risks faced by inbound and domestic tourists during the tourist activities. As the stay time of foreign tourists is usually longer than that of domestic tourists, inbound tourists are potentially exposed to more $\mathrm{NO}_{2}$ when they visit polluted cities. Therefore, inbound tourists might become more responsive to the variations of pollution. For example, Song et al. [61] demonstrated increasing prevalence trends of adult asthma in Asian regions, especially in Japan and South Korea, which are the top source countries of China's inbound tourism. Given that exposure to $\mathrm{NO}_{2}$ could lead to asthma exacerbations [62], it is possible that people 
with potential asthma or other respiratory diseases would stay away from travel destinations with high $\mathrm{NO}_{2}$ concentrations.

It is notable that, although our study did not report as significant a harmful impact of $\mathrm{PM}_{10}, \mathrm{SO}_{2}$, or $\mathrm{NO}_{2}$ on tourism as $\mathrm{PM}_{2.5}$, this does not necessarily mean that these three pollutants are trivial to sustainable tourism development in China. From the perspective of public health, the threats to tourists' health conditions posed by $\mathrm{PM}_{10}, \mathrm{SO}_{2}$, and $\mathrm{NO}_{2}$ should be noticed. It is also notable that, since the inference from our regressions reflects an average situation based on a sample of 337 Chinese cities, it does not rule out idiosyncratic properties in different areas. It is possible that, although $\mathrm{PM}_{2.5}$ is the most adverse pollutant on average, pollution problems in certain regions are majorly caused by other pollutants. The unequal impacts of different pollutants on tourism detected by our study essentially indicate that tourism-relevant policy makers and researchers should pay attention to monitoring suitable air pollution indictors. In particular, $\mathrm{PM}_{2.5}$ should not be ignored in tourism analysis.

The third finding was that domestic tourists and inbound tourists respond to air pollution at different magnitudes. According to our estimates, if $\mathrm{PM}_{2.5}$ concentration rises by $1 \mu \mathrm{g} / \mathrm{m}^{3}$, domestic and inbound tourist arrivals will decline by $0.482 \%$ and $1.227 \%$, respectively. Thus, in terms of percentage change, inbound tourists are more sensitive to the degradation of air quality. It is plausible that foreign travelers are more aware of the harmfulness of air pollution, compared to Chinese travelers. An earlier study by Law and Cheung [33] has signaled that travelers from Western countries were more sensitive to the air pollution in Hong Kong than Asian travelers. Our study extends the result of Law and Cheung [33], which used Hong Kong as a case study, to a large geographic scope. In addition, it should be noticed that, as the aggregate size of domestic tourism is much larger than inbound tourism in China, in absolute values, the impact of air pollution on domestic tourism is much stronger. Our estimates imply a reduction of 81,855 person-times in annual domestic tourist arrivals and 12,269 in inbound tourist arrivals, in response to a $1 \mu \mathrm{g} / \mathrm{m}^{3}$ increase in $\mathrm{PM}_{2.5}$. These estimates could help the tourism sectors predict the trends and variations of domestic and inbound tourism development associated with varying air quality problems. Moreover, these estimates could not only exert pressure on policy makers to improve environmental outcomes, but also raise Chinese citizens' awareness of environmental protection to build a positive destination image.

\subsection{Implications}

From a theoretical perspective, this study made the following contributions. First, this study empirically examined the impacts of four important components of air pollution $\left(\mathrm{PM}_{2.5}, \mathrm{PM}_{10}, \mathrm{SO}_{2}\right.$, and $\mathrm{NO}_{2}$ ) on both the domestic and inbound tourism industries in China using a sample of 337 cities covering the period between 2007 and 2016. The sample used in the study may generate more precise and updated estimates, since it covers the period of recent years for a wide geographic range. Second, the findings enrich the air pollution-tourism nexus literature by confirming the finding from previous research that $\mathrm{PM}_{2.5}$ plays a vital role in depressing both domestic and inbound tourist numbers in China, and by providing new insights into how $\mathrm{NO}_{2}$ exerts different effects on the domestic and inbound tourism industries. The study results remind researchers that air pollution might be more accurately studied from the perspective of different air pollutants.

Practically, the results indicate that the Chinese government should continue tackling air pollution in China for the benefit of human health and for the sustainable development of the tourism industry. On the one hand, among the four common air pollutants considered, it seems that $\mathrm{PM}_{2.5}$ has received the most attention from travelers over the last decade. Therefore, tourism policy makers should primarily focus on $\mathrm{PM}_{2.5}$, concerning the nexus between air quality and the development of tourism. On the other hand, given the fact that other air pollutants could also result in negative health effects, emphasizing the importance of $\mathrm{PM}_{2.5}$ should not overshadow the threats posed by other air pollutants. It is suggested that great efforts should be made to raise travelers' awareness of other air pollutants. Furthermore, although China's outbound tourism market has attracted the attention of the world, its inbound tourism has been experiencing very slow growth [63]. As suggested by this study, $\mathrm{NO}_{2}$ 
pollution should also be tackled to attract more international travelers. The estimation results also reveal that inbound tourists are more sensitive to the air pollution issue in China. Given that Beijing, the capital of China with notorious air quality records, has attracted a lot of international attention in recent years, inbound tourists may believe that the air quality in other Chinese cities is also poor. In fact, there are a number of Chinese tourist cities with air quality up to standard, including Haikou, Zhoushan, Lhasa, Fuzhou, Zhuhai, and Huizhou, among others [64]. Destination marketers in China could strive to promote these cities to potential inbound tourists and design more haze-avoidance or smog-free travel packages.

\section{Conclusions and Directions for Future Research}

To conclude, the present study utilized an econometric model to empirically investigate how four atmospheric pollutants $\left(\mathrm{PM}_{2.5}, \mathrm{PM}_{10}, \mathrm{SO}_{2}\right.$, and $\left.\mathrm{NO}_{2}\right)$ affected the tourism industry in China. The results of the analyses demonstrated that $\mathrm{PM}_{2.5}$ played a dominant role in negatively influencing China's inbound and domestic tourism industries. The results also revealed that $\mathrm{NO}_{2}$ reduced the number of inbound tourists.

This study was restricted by several limitations, which actually indicate promising directions for future research. Firstly, some other air pollutants, such as $\mathrm{CO}$ (carbon monoxide) and $\mathrm{O}_{3}$ (ozone), were not investigated in this study due to the limitation of data availability. These two pollutants are also monitored and reported by the environmental sectors of the government in China. Unfortunately, data are only available for a very small sample from our data sources. In the future, the impact of other air pollutants could also be inspected if more data can be collected.

Secondly, this study examined the effects of different air pollutants but did not consider any comprehensive air pollution indices, such as AQI. Estimating the impact of AQI on tourism and comparing it with the estimated impact of $\mathrm{PM}_{2.5}$ will provide more information for better decision making. However, in this study, we were not able to do this because of the data availability problem. Given that AQI was not directly available from our data sources, in order to infer the values of AQI, we need to know the values of different pollutants, including $\mathrm{PM}_{2.5}, \mathrm{PM}_{10}, \mathrm{SO}_{2}, \mathrm{NO}_{2}, \mathrm{CO}$, and $\mathrm{O}_{3}$. On the one hand, as mentioned previously, there were no sufficient data of $\mathrm{CO}$ and $\mathrm{O}_{3}$. On the other hand, our $\mathrm{PM}_{2.5}$ data provided by NASA were constructed based on the remote sensing measurements of satellites. The data are not directly comparable to those provided by the MEP and MEE based on direct measurements in different local observation stations, though they are both reliable and highly correlated. Hence, we can investigate the correlation between AQI and tourism in the future, after more data are released.

Thirdly, this study inspected the actual level of air pollution measured by scientific instruments. It is notable that the objectively measured air pollution level might not be completely consistent with people's perceived level of air pollution, since the perception of air pollution is subjective and affected by a lot of social and individual factors, such as education and mass media. Future studies could collect data on the perceived air pollution level by potential tourists and examine whether the study results using subjective data match the results in this study.

Author Contributions: Conceptualization and funding acquisition, D.D. and X.X.; methodology, data curation, formal analysis, and original draft preparation, D.D.; literature review and review and editing, X.X.; software, validation, and supervision, Y.W. and S.W.

Funding: This research was funded by the Fundamental Research Funds for the Central Universities (grant numbers JBK1801039 and JBK1809054).

Acknowledgments: The authors are grateful to the Editors and two anonymous referees for their comments and suggestions.

Conflicts of Interest: The authors declare no conflict of interest. 


\section{References}

1. Kao, E. Air pollution is killing 1 million people and costing Chinese economy 267 billion yuan a year, research from CUHK shows. South China Morning Post, 2 October 2018.

2. Becken, S.; Jin, X.; Zhang, C.; Gao, J. Urban air pollution in China: destination image and risk perceptions. J. Sustain. Tour. 2017, 25, 130-147. [CrossRef]

3. Poudyal, N.C.; Paudel, B.; Green, G.T. Estimating the Impact of Impaired Visibility on the Demand for Visits to National Parks. Tour. Econ. 2013, 19, 433-452. [CrossRef]

4. Zhang, Y.; Khan, S.A.R.; Kumar, A.; Golpîra, H.; Sharif, A. Is tourism really affected by logistical operations and environmental degradation? An empirical study from the perspective of Thailand. J. Clean. Prod. 2019, 227, 158-166. [CrossRef]

5. Zhang, A.; Zhong, L.; Xu, Y.; Wang, H.; Dang, L. Tourists' Perception of Haze Pollution and the Potential Impacts on Travel: Reshaping the Features of Tourism Seasonality in Beijing, China. Sustainability 2015, 7, 2397-2414. [CrossRef]

6. Héroux, M.E.; Anderson, H.R.; Atkinson, R.; Brunekreef, B.; Cohen, A.; Forastiere, F.; Hurley, F.; Katsouyanni, K.; Krewski, D.; Krzyzanowski, M.; et al. Quantifying the health impacts of ambient air pollutants: recommendations of a WHO/Europe project. Int. J. Public Health 2015, 60, 619-627. [CrossRef] [PubMed]

7. Khaniabadi, Y.O.; Goudarzi, G.; Daryanoosh, S.M.; Borgini, A.; Tittarelli, A.; De Marco, A. Exposure to PM10, $\mathrm{NO}_{2}$, and $\mathrm{O}_{3}$ and impacts on human health. Environ. Sci. Pollut. Res. 2017, 24, 2781-2789. [CrossRef]

8. Yan, L.; Duarte, F.; Wang, D.; Zheng, S.; Ratti, C. Exploring the effect of air pollution on social activity in China using geotagged social media check-in data. Cities 2019, 91, 116-125. [CrossRef]

9. Dong, D.; Xu, X.; Wong, Y.F. Estimating the Impact of Air Pollution on Inbound Tourism in China: An Analysis Based on Regression Discontinuity Design. Sustainability 2019, 11, 1682. [CrossRef]

10. Dong, D.; Xu, X.; Yu, H.; Zhao, Y. The Impact of Air Pollution on Domestic Tourism in China: A Spatial Econometric Analysis. Sustainability 2019, 11, 4148. [CrossRef]

11. Liu, J.; Pan, H.; Zheng, S. Tourism Development, Environment and Policies: Differences between Domestic and International Tourists. Sustainability 2019, 11, 1390. [CrossRef]

12. Sun, J.; Zhang, J.H.; Wang, C.; Duan, X.; Wang, Y. Escape or stay? Effects of haze pollution on domestic travel: Comparative analysis of different regions in China. Sci. Total Environ. 2019, 690, 151-157. [CrossRef] [PubMed]

13. Guindi, M.N.; Flaherty, G.T.; Byrne, M. Every breath you take: how does air pollution affect the international traveller? J. Travel Med. 2018, 25, 1-3. [PubMed]

14. Emami, F.; Masiol, M.; Hopke, P.K. Air pollution at Rochester, NY: Long-term trends and multivariate analysis of upwind SO2 source impacts. Sci. Total Environ. 2018, 612, 1506-1515. [CrossRef] [PubMed]

15. Lu, Q.; Zheng, J.; Ye, S.; Shen, X.; Yuan, Z.; Yin, S. Emission trends and source characteristics of $\mathrm{SO}_{2}$, NOx, PM10 and VOCs in the Pearl River Delta region from 2000 to 2009. Atmos. Environ. 2013, 76, 11-20. [CrossRef]

16. World Health Organizations. Ambient (Outdoor) Air Quality and Health. 2018. Available online: https: / / www.who.int/news-room/fact-sheets/detail/ambient-(outdoor)-air-quality-and-health (accessed on 10 September 2019).

17. Liu, F.; Beirle, S.; Zhang, Q.; van der A, R.J.; Zheng, B.; Tong, D.; He, K. NOx emission trends over Chinese cities estimated from OMI observations during 2005 to 2015. Atmos. Chem. Phys. 2017, 17, 9261-9275. [CrossRef]

18. Hamra, G.B.; Laden, F.; Cohen, A.J.; Raaschou-Nielsen, O.; Brauer, M.; Loomis, D. Lung Cancer and Exposure to Nitrogen Dioxide and Traffic: A Systematic Review and Meta-Analysis. Environ. Health Perspect. 2015, 123, 1107-1112. [CrossRef]

19. Mehta, P. Science behind Acid Rain: Analysis of Its Impacts and Advantages on Life and Heritage Structures. South Asian J. Tour. Heritage 2010, 3, 123-132.

20. Wong, E. Outlasting Dynasties, Now Emerging from Soot. The New York Times, 18 May 2014.

21. Wang, H.; Zhuang, Y.; Wang, Y.; Sun, Y.; Yuan, H.; Zhuang, G.; Hao, Z. Long-term monitoring and source apportionment of PM2.5/PM10 in Beijing, China. J. Environ. Sci. 2008, 20, 1323-1327. [CrossRef] 
22. Agudelo-Castañeda, M.D.; Calesso Teixeira, E.; Alves, L.; Fernández-Niño, A.J.; Rodríguez-Villamizar, A.L. Monthly-Term Associations Between Air Pollutants and Respiratory Morbidity in South Brazil 2013-2016: A Multi-City, Time-Series Analysis. Int. J. Environ. Res. Public Health 2019, 16, 3787. [CrossRef]

23. Merklinger-Gruchala, A.; Jasienska, G.; Kapiszewska, M. Effect of Air Pollution on Menstrual Cycle Length-A Prognostic Factor of Women's Reproductive Health. Int. J. Environ. Res. Public Health 2017, 14, 816. [CrossRef]

24. Shin, J.; Han, S.H.; Choi, J. Exposure to Ambient Air Pollution and Cognitive Impairment in Community-Dwelling Older Adults: The Korean Frailty and Aging Cohort Study. Int. J. Environ. Res. Public Health 2019, 16, 3767. [CrossRef] [PubMed]

25. Lu, F.; Xu, D.; Cheng, Y.; Dong, S.; Guo, C.; Jiang, X.; Zheng, X. Systematic review and meta-analysis of the adverse health effects of ambient PM2.5 and PM10 pollution in the Chinese population. Environ. Res. 2015, 136, 196-204. [CrossRef] [PubMed]

26. Feng, C.; Li, J.; Sun, W.; Zhang, Y.; Wang, Q. Impact of ambient fine particulate matter (PM2.5) exposure on the risk of influenza-like-illness: a time-series analysis in Beijing, China. Environ. Health 2016, 15, 17. [CrossRef] [PubMed]

27. Lin, Y.; Zou, J.; Yang, W.; Li, C.Q. A Review of Recent Advances in Research on PM2.5 in China. Int. J. Environ. Res. Public Health 2018, 15, 438. [CrossRef]

28. Xu, X.; Reed, M. Perceived pollution and inbound tourism in China. Tour. Manag. Perspect. 2017, 21, 109-112. [CrossRef]

29. Xu, X.; Reed, M. Perceived pollution and inbound tourism for Shanghai: a panel VAR approach. Curr. Issues Tour. 2019, 22, 601-614. [CrossRef]

30. Deng, T.; Li, X.; Ma, M. Evaluating impact of air pollution on China's inbound tourism industry: A spatial econometric approach. Asia Pac. J. Tour. Res. 2017, 22, 771-780. [CrossRef]

31. Anaman, K.A.; Looi, C.N. Economic Impact of Haze-Related Air Pollution on the Tourism Industry in Brunei Darussalam. Econ. Anal. Policy 2000, 30, 133-143. [CrossRef]

32. Chen, C.M.; Lin, Y.L.; Hsu, C.L. Does air pollution drive away tourists? A case study of the Sun Moon Lake National Scenic Area, Taiwan. Transp. Res. Part D Transp. Environ. 2017, 53, 398-402. [CrossRef]

33. Law, R.; Cheung, C. Air Quality in Hong Kong: A Study of the Perception of International Visitors. J. Sustain. Tour. 2007, 15, 390-401. [CrossRef]

34. Li, J.; Pearce, P.L.; Morrison, A.M.; Wu, B. Up in Smoke? The Impact of Smog on Risk Perception and Satisfaction of International Tourists in Beijing. Int. J. Tour. Res. 2016, 18, 373-386. [CrossRef]

35. Peng, J.; Xiao, H. How does smog influence domestic tourism in China? A case study of Beijing. Asia Pac. J. Tour. Res. 2018, 23, 1115-1128. [CrossRef]

36. Qiao, G.; Peng, S.; Prideaux, B.; Qiao, M. Identifying Causes for the Decline in International Arrivals to China-Perspective of Sustainable Inbound Tourism Development. Sustainability 2019, 11, 1723. [CrossRef]

37. Tang, J.; Yuan, X.; Ramos, V.; Sriboonchitta, S. Does air pollution decrease inbound tourist arrivals? The case of Beijing. Asia Pac. J. Tour. Res. 2019, 24, 597-605. [CrossRef]

38. Wang, M.C.; Wang, C.S. Tourism, the environment, and energy policies. Tour. Econ. 2018, 24, 821-838. [CrossRef]

39. Wang, L.; Fang, B.; Law, R. Effect of air quality in the place of origin on outbound tourism demand: Disposable income as a moderator. Tour. Manag. 2018, 68, 152-161. [CrossRef]

40. Xu, D.; Huang, Z.; Hou, G.; Zhang, C. The spatial spillover effects of haze pollution on inbound tourism: evidence from mid-eastern China. Tour. Geogr. 2019, pp. 1-22. [CrossRef]

41. Yoon, H. Effects of particulate matter (PM10) on tourism sales revenue: A generalized additive modeling approach. Tour. Manag. 2019, 74, 358-369. [CrossRef]

42. Zhou, B.; Qu, H.; Du, X.; Yang, B.; Liu, F. Air Quality and Inbound Tourism in China. Tour. Anal. 2018, 23, 159-164. [CrossRef]

43. Zhou, X.; Santana Jiménez, Y.; Pérez Rodríguez, J.V.; Hernández, J.M. Air pollution and tourism demand: A case study of Beijing, China. Int. J. Tour. Res. 2019, 21, 747-757. [CrossRef]

44. Stiebale, J. Do Financial Constraints Matter for Foreign Market Entry? A Firm-level Examination. World Econ. 2011, 34, 123-153. [CrossRef]

45. Vergara, R. Taxation and private investment: evidence for Chile. Appl. Econ. 2010, 42, 717-725. [CrossRef] 
46. van Donkelaar, A.; Martin, R.V.; Brauer, M.; Hsu, N.C.; Kahn, R.A.; Levy, R.C.; Lyapustin, A.; Sayer, A.M.; Winker, D.M. Global Estimates of Fine Particulate Matter Using a Combined Geophysical-Statistical Method with Information from Satellites. Environ. Sci. Technol. 2016, 50, 3762-3772. [CrossRef] [PubMed]

47. van Donkelaar, A.; Martin, R.V.; Brauer, M.; Hsu, N.C.; Kahn, R.A.; Levy, R.C.; Lyapustin, A.; Sayer, A.M.; Winker, D.M. Global Annual PM2.5 Grids from MODIS, MISR and SeaWiFS Aerosol Optical Depth (AOD) with GWR, 1998-2016; NASA Socioeconomic Data and Applications Center (SEDAC): Palisades, NY, USA, 2018. [CrossRef]

48. Ministry of Environmental Protection of the People's Republic of China. The Report on the State of the Environment of China 2007, 2008, 2009, 2010, 2011; Published in Sequent Years, in Chinese; China Environmental Science Press: Beijing, China, 2008-2012.

49. Ministry of Environmental Protection of the People's Republic of China. The Report on the State of the Environment of China 2012, 2014; Published in Separate Years, In Chinese; China Environment Press: Beijing, China, 2013, 2015.

50. Ministry of Ecology and Environment of the People's Republic of China. The Report on the State of the Environment of China 2016; China Environment Publishing Group: Beijing, China, 2018. (In Chinese)

51. Hu, J.; Ying, Q.; Wang, Y.; Zhang, H. Characterizing multi-pollutant air pollution in China: Comparison of three air quality indices. Environ. Int. 2015, 84, 17-25. [CrossRef]

52. Wesson, K.; Fann, N.; Morris, M.; Fox, T.; Hubbell, B. A multi-pollutant, risk-based approach to air quality management: Case study for Detroit. Atmos. Pollut. Res. 2010, 1, 296-304. [CrossRef]

53. Holden, A. The environment-tourism nexus: Influence of market ethics. Ann. Tour. Res. 2009, 36, 373-389. [CrossRef]

54. Kay, S.; Zhao, B.; Sui, D. Can Social Media Clear the Air? A Case Study of the Air Pollution Problem in Chinese Cities. Prof. Geogr. 2015, 67, 351-363. [CrossRef]

55. Kim, Y.J.; Kim, K.W.; Oh, S.J. Seasonal Characteristics of Haze Observed by Continuous Visibility Monitoring in the Urban Atmosphere of Kwangju, Korea. Environ. Monit. Assess. 2001, 70, 35-46. [CrossRef]

56. Ge, W.; Chen, R.; Song, W.; Kan, H. Daily Visibility and Hospital Admission in Shanghai, China. Biomed. Environ. Sci. 2011, 24, 117-121. [CrossRef]

57. Kirillova, K.; Fu, X.; Lehto, X.; Cai, L. What makes a destination beautiful? Dimensions of tourist aesthetic judgment. Tour. Manag. 2014, 42, 282-293. [CrossRef]

58. Zhuang, P. Hundreds of flights cancelled in Beijing as thick smog lays siege to capital. South China Morning Post, 20 December 2016.

59. Guo, Y.; Liu, F.; Lu, Y.; Mao, Z.; Lu, H.; Wu, Y.; Chu, Y.; Yu, L.; Liu, Y.; Ren, M.; Li, N.; Chen, X.; Xiang, H. Factors Affecting Parent's Perception on Air Quality-From the Individual to the Community Level. Int. J. Environ. Res. Public Health 2016, 13, 493. [CrossRef]

60. Reames, T.G.; Bravo, M.A. People, place and pollution: Investigating relationships between air quality perceptions, health concerns, exposure, and individual- and area-level characteristics. Environ. Int. 2019, 122, 244-255. [CrossRef] [PubMed]

61. Song, W.J.; Kang, M.G.; Chang, Y.S.; Cho, S.H. Epidemiology of adult asthma in Asia: toward a better understanding. Asia Pac. Allergy 2014, 4, 75-85. [CrossRef] [PubMed]

62. Orellano, P.; Quaranta, N.; Reynoso, J.; Balbi, B.; Vasquez, J. Effect of outdoor air pollution on asthma exacerbations in children and adults: Systematic review and multilevel meta-analysis. PLoS ONE 2017, 12, e0174050. [CrossRef] [PubMed]

63. Cheng, S. Inbound tourism still rising. China Daily, 23 May 2018.

64. Ministry of Environmental Protection of the People's Republic of China. MEP Releases Air Quality of Key Regions and 74 Cities in September and Q3 of 2013. Available online: http:/ / english.mee.gov.cn/News service/news_release/201310/t20131024_262189.shtml (accessed on 10 September 2019).

(C) 2019 by the authors. Licensee MDPI, Basel, Switzerland. This article is an open access article distributed under the terms and conditions of the Creative Commons Attribution (CC BY) license (http:/ / creativecommons.org/licenses/by/4.0/). 